\title{
ENDOTHELIAL DYSFUNCTION IN TYPE 2 DIABETES MELLITUS AND ITS RELATION WITH GLYCAEMIC CONTROL- RESULTS OF AN OBSERVATIONAL STUDY
}

\author{
Vinayak M. Sawardekar1, Rohit Patil2, Rajesh V. Gosavi3 ${ }^{3}$ Pramod Gandhi', Swapnali Hankare ${ }^{5}$, V. K. Joglekar6, Shriram Nawade ${ }^{7}$, \\ Nikhil Badnerkar ${ }^{8}$
}

\begin{abstract}
${ }^{1}$ Associate Professor, Department of Medicine, Grant Government Medical College \& Sir JJ Group of Hospitals, Mumbai. ${ }^{2} 3^{r d}$ Year Junior Resident, Department of Medicine, Grant Government Medical College \& Sir JJ Group of Hospitals, Mumbai. ${ }_{3}^{3}$ Associate Professor, Department of Medicine, Indira Gandhi Government Medical College, Nagpur.

${ }^{4}$ Consulting Endocrinologist, Indira Gandhi Government Medical College, Nagpur.

$53^{\text {rd }}$ Year Junior Resident, Department of Anaesthesia, LTMMC \& LTMGH, Sion, Mumbai.

${ }_{6}$ Professor \& HOD, Department of Medicine, Grant Government Medical College \& Sir JJ Group of Hospitals, Mumbai.

73rd Year Junior Resident, Department of Medicine, Grant Government Medical College \& Sir JJ Group of Hospitals, Mumbai. ${ }^{8}$ Assistant Professor, Department of Medicine, Indira Gandhi Government Medical College, Nagpur.
\end{abstract}

ABSTRACT
BACKGROUND
The aim of the study is to examine endothelial dysfunction in type 2 diabetes with inadequate glycaemic control and to study
improvement in endothelial function after glycaemic control.

\section{MATERIALS AND METHODS}

An observational study was performed in type 2 diabetic patients (35-60 years) with inadequate glycaemic control. Endothelial function was evaluated by non-invasive method. Flow associated dilation (\%FAD) change in lumen diameter of brachial artery after glyceryl trinitrate spray (\%GTN) were calculated. After achieving glycaemic control for $>3$ months, HbA1c and endothelial function test were compared with baseline.

\section{RESULTS}

Out of 73 patients (mean age $50.79 \pm 4.96$ years) enrolled, $46.5 \%$ were male and $41.09 \%$ were overweight. The mean duration of diabetes was $4.84 \pm 3.2$ years. Significant difference was noted in HbA1c, fasting blood glucose and postprandial blood glucose after treatment ( $\mathrm{p}<0.05$ for all). Mean \%FAD before glycaemic control was $7.34 \pm 2.16$ whereas mean \% GTN was $14.60 \pm 2.96$; $89 \%$ patients had \% FAD $<10 \%$. Significant improvement was observed in \%FAD after glycaemic control (p<0.05) but not in \%GTN $(\mathrm{p}=0.47)$. Percentage FAD significantly increased after glycaemic control in patients with HbA1c $<7 \%(\mathrm{p}<0.05)$. No significant difference was seen in \% GTN in patients with HbA1c less than or more than $7 \%(\mathrm{p}>0.05)$. \%FAD did not improve in patients with baseline HbA1c > 7\% ( $>0.05)$. After anti-diabetic therapy, reduction in HbA1c $(p<0.05)$ and \%improvement in FAD ( $<<0.01)$ was better in patients with baseline HbA1c $<7 \%$ compared to those with $>7 \%$. HbA1c and body mass index had significantly negative correlation with \%FAD before as well as after glycaemic control.

\section{CONCLUSION}

Uncontrolled type 2 diabetes mellitus is associated with impaired endothelial function. Negative correlation is observed between endothelial dysfunction and glycaemic status of type 2 diabetes patients. Glycaemic control results in improvement of endothelial dysfunction.

\section{KEYWORDS}

Endothelial Dysfunction, Glycaemic Control, Type 2 Diabetes Mellitus.

HOW TO CITE THIS ARTICLE: Sawardekar VM, Patil R, Gosavi RV, et al. Endothelial dysfunction in type 2 diabetes mellitus and its relation with glycaemic control- Results of an observational study. J. Evolution Med. Dent. Sci. 2017;6(11):857-861, DOI: $10.14260 /$ Jemds/2017/185

\section{BACKGROUND}

Diabetes is a growing concern across the world and more so in India because of high prevalence and associated complications. About 65.1 million people between 20-79 years in India have diabetes resulting in prevalence of

Financial or Other, Competing Interest: None.

Submission 12-01-2017, Peer Review 24-01-2017,

Acceptance 28-01-2017, Published 02-02-2017.

Corresponding Author:

Dr. Vinayak M. Sawardekar

Associate Professor

Department of Medicine,

Grant Government Medical College \&

Sir JJ Group of Hospitals, Mumbai.

E-mail: vinayaks1812@gmail.com

DOI: $10.14260 /$ jemds $/ 2017 / 185$

8.56\%. Microvascular and macrovascular complications of diabetes are very well documented. ${ }^{1}$ Cardiovascular disease is one of the major complications of diabetes mellitus. ${ }^{2}$ Diabetes is associated with two to four times more risk of cardiovascular diseases. Vascular endothelium plays dual role in maintaining cardiovascular health. It offers protection by acting as a physical barrier between vessel wall and its lumen and also by release of several mediators. Endothelial dysfunction results in loss of physiological properties of the endothelium rendering person vulnerable to the diabetes related complications. ${ }^{1}$ Endothelial dysfunction is known to play a very important role in the pathogenesis of diabetes related complications. Hyperglycaemia is the main cause for endothelial dysfunction in diabetes mellitus. ${ }^{3}$ It is also postulated that oxidative stress may precede the development of endothelial dysfunction. ${ }^{4}$ Similarly, increased 
levels of lipids, hs-CRP, intimal medial thickening, reduced nitrite levels, could also contribute to the risk of endothelial dysfunction in these patients. ${ }^{5}$ Improved strategies for prevention and treatment of cardiovascular disease in diabetes patients are needed. In this regard, endothelial function can be a useful prognostic marker.3,6 The data about the impact of glycaemic control on endothelial dysfunction in Indian type 2 diabetes patient are limited.

\section{Objective}

The objective of the current study was to examine endothelial dysfunction in cases of type 2 diabetes with inadequate glycaemic control and to compare change in endothelial function before and after adequate glycaemic control.

\section{MATERIALS AND METHODS}

This observational study was performed in adult type 2 diabetic patients between 35 to 60 years of age with inadequate glycaemic control i.e. glycosylated haemoglobin (HbA1c) more than 7\% and duration not more than 15 years attending outpatient clinic or admitted in wards from December 2007 to July 2009. Patients with coronary vascular disease, hypertension, peripheral vascular disease, smokers, those with renal failure (Defined as serum creatinine $>2 \mathrm{mg} \%$ ), sickle cell disease, evidence of any acute infectious, inflammatory or severe concurrent illness and body mass index (BMI) $\geq 40 \mathrm{~kg} / \mathrm{m}^{2}$ were excluded. Similarly, patients with history of cerebrovascular episodes were also not included in the present study.

After complete clinical examination, all patients underwent investigations including fasting blood glucose, serum creatinine, serum electrolytes and fasting lipid profile. A resting twelve lead electrocardiogram was recorded in every patient. Enrolled patients were evaluated for endothelial function by non-invasive method and regularly followed up in diabetic outpatient clinic. Their treatment pattern, compliance to treatment and blood glucose levels were reviewed regularly for ensuring stabilisation of controlled blood glucose levels. Treatment was modified for control of blood glucose levels by adding or changing oral hypoglycaemic agents. Dosages of insulin were modified for cases who were on already on insulin (Regular or NPH) for achieving glycaemic control. These drugs were used for achieving control of blood glucose levels and trying to avoid hypoglycaemic episodes. After achieving glycaemic control for more than three months, HbA1c and endothelial function test were repeated and compared with baseline readings. Assessment of endothelial function was done by Doppler study of brachial artery as described by Celermajer et al (1992) ${ }^{7}$ and found useful in Indian patients. ${ }^{8}$ In this study, diameter of brachial artery was assessed by vascular Doppler probe of 7.5 to $10 \mathrm{MHz}$ of Esaote Megas GP 2-D Echo and Doppler machine. The measurement of the brachial artery diameter was scanned in supine position, right brachial artery $2-5 \mathrm{~cm}$ above the elbow. The scanned area was marked to measure the same segment of brachial artery repeatedly and changes in the diameter will be noted. The readings were taken for four times.

\begin{tabular}{|c|c|}
\hline Reading & Time of reading \\
\hline First & $\begin{array}{c}\text { The patient was allowed to rest for } \\
10 \text { minutes and first reading taken }\end{array}$ \\
\hline Second & $\begin{array}{c}\text { Reactive hyperaemia: The cuff was inflated } \\
\text { by pneumatic tourniquet for four minutes } \\
\text { till } 300 \text { mmHg of pressure over forearm } \\
\text { and reading was taken within one } \\
\text { minute of cuff deflation }\end{array}$ \\
\hline Third & After 15 minutes of rest \\
\hline Fourth & $\begin{array}{c}\text { After glyceryl trinitrate (GTN) spray: } \\
\text { Reading was taken after } \\
\text { 3-4 minutes of consumption of } \\
\text { Table 1. Recordings of Brachial Artery Diameter }\end{array}$ \\
\hline
\end{tabular}

Flow associated dilation (\%FAD) was calculated as change in lumen diameter (LD) of brachial artery (BA) after reactive hyperaemia from reading at rest. Change in lumen diameter of brachial artery (BA) after glyceryl trinitrate (GTN) spray (\%GTN) from reading at rest was also calculated.

Endothelial dysfunction was defined as \%FAD less than $10 \%{ }^{9}$ whereas glycaemic control was defined as fasting blood glucose $\leq 120 \mathrm{mg} / \mathrm{dL}$ and postprandial blood glucose $\leq 180$ $\mathrm{mg} \%$.

\section{Statistical Analysis}

Continuous variables are presented as mean and standard deviation whereas categorical variables are given as percentages. Significance of difference between means of two independent groups was assessed by using unpaired ' $t$ ' test whereas paired ' $t$ ' test was applied for comparing the differences in means of the same groups. Pearson's correlation coefficient $(r)$ was calculated for studying the relationship between two continuous variables, the significance of which was tested with a ' $t$ ' test. $P$ value of $<0.05$ was considered as statistically significant.

\section{RESULTS}

A total of 73 inadequately controlled type 2 diabetes patients were enrolled in the study. Thirty four patients (46.5\%) were male and thirty nine (53.4\%) were female. The mean \pm SD age of patients in this study was $50.79 \pm 4.96$ years. A total of forty-seven (64.38\%) patients were in age group of 45 to 55 years. The number (\%) of patients between 35 to 45 years and 55 to 60 years were $14(19.17 \%)$ and $12(16.43 \%)$ respectively.

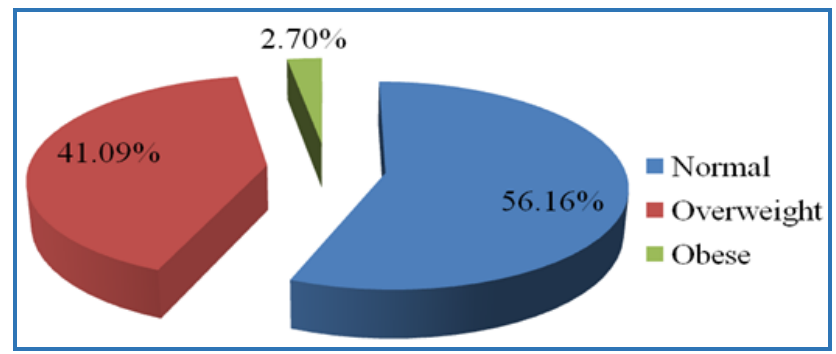

Figure 1. Distribution of Cases According to BMI

Normal: $18.5-24.99 \mathrm{~kg} / \mathrm{m}^{2}$; Overweight: $25-29.99 \mathrm{~kg} / \mathrm{m}^{2}$; Obese: $30-39.99 \mathrm{~kg} / \mathrm{m}^{2}$.

A total of $56.16 \%$ patients had normal body mass index (BMI) while $41.09 \%$ were overweight (Figure 1). Forty eight 
(65.75\%) patients were having type 2 diabetes since less than or equal to five years whereas $27.39 \%$ patients had diabetes between five to ten years. Remaining patients (6.84\%) had diabetes between 10 to 15 years. The mean duration of diabetes was $4.84 \pm 3.2$ years. At baseline, 36 (49.31\%), 20 (27.39\%) and $17(23.3 \%)$ patients had HbA1c level between $7-8 \%, 8-9 \%$ and $>9 \%$ respectively.

\begin{tabular}{|c|c|}
\hline Parameter & Result \\
\hline Mean BMI (kg/m²) & $24.67 \pm 1.75$ \\
\hline HbA1c (\%) & $8.39 \pm 1.48$ \\
\hline Fasting Blood Sugar (mg/dL) & $134.73 \pm 41.5$ \\
\hline Postprandial Blood Sugar (mg/dL) & $205.53 \pm 50.36$ \\
\hline Total Cholesterol (TC) (mg/dL) & $169.95 \pm 33.32$ \\
\hline Triglycerides (TG) (mg/dL) & $131.31 \pm 44.62$ \\
\hline $\begin{array}{c}\text { Low Density Lipoproteins } \\
\text { (LDL) (mg/dL) }\end{array}$ & $100.05 \pm 30.75$ \\
\hline $\begin{array}{c}\text { Very Low Density } \\
\text { Lipoproteins (VLDL) (mg/dL) }\end{array}$ & $26.34 \pm 9.03$ \\
\hline $\begin{array}{c}\text { High Density Lipoproteins } \\
\text { (HDL) (mg/dL) }\end{array}$ & $43.56 \pm 6.93$ \\
\hline $\begin{array}{c}\text { Table 2. Baseline Characteristics before } \\
\text { Glycaemic Control (at the time of enrolment) }\end{array}$ \\
\hline
\end{tabular}

Baseline characteristics of patients before glycaemic control are shown in table 2 .

\begin{tabular}{|c|c|c|c|}
\hline & $\begin{array}{c}\text { Before } \\
\text { Treatment } \\
\text { (n=73) }\end{array}$ & $\begin{array}{c}\text { After } \\
\text { Treatment } \\
\text { (n=73) }\end{array}$ & $\begin{array}{c}\text { P } \\
\text { Value }\end{array}$ \\
\hline HbA1c (\%) & $8.39 \pm 1.48$ & $7.24 \pm 1.25$ & $<0.05$ \\
\hline $\begin{array}{c}\text { Fasting Blood } \\
\text { Glucose (mg/dL) }\end{array}$ & $134.73 \pm 41.5$ & $116.3 \pm 31.5$ & $<0.05$ \\
\hline $\begin{array}{c}\text { Postprandial Blood } \\
\text { Glucose (mg/dL) }\end{array}$ & $205.53 \pm 50.36$ & $171.3 \pm 36.7$ & $<0.05$ \\
\hline \multicolumn{3}{|c|}{ Table 3. Glycaemic Control Post-treatment } \\
with Anti-diabetic Medications \\
\hline
\end{tabular}

Significant difference was noted between glycaemic parameters i.e. HbA1c, fasting blood glucose and postprandial blood glucose after treatment (Table 3).

Mean \%FAD before glycaemic control was $7.34 \pm 2.16$ whereas mean $\%$ GTN was $14.60 \pm 2.96$.

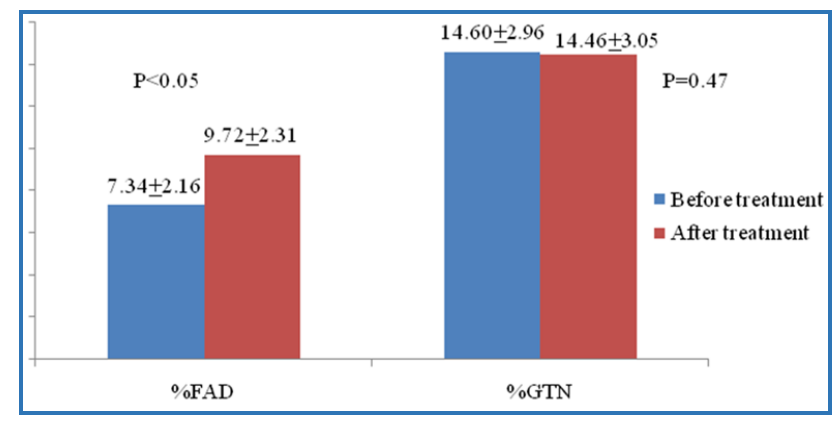

Figure 2. Endothelial Function before and after Glycaemic Control

Significant improvement was observed in endotheliumdependent dilation (\%FAD) after glycaemic control (Figure 2; $\mathrm{p}<0.05$ ) whereas $\%$ GTN did not show significant difference after glycaemic control $(\mathrm{p}=0.47)$. Before glycaemic control, 65
$(89 \%)$ cases had endothelial dysfunction (\%FAD <10\%) which reduced to 39 (53.4\%) cases after glycaemic control, showing endothelial function improvement in 26 cases after glycaemic control. After three months of treatment, 50 (68.5\%) patients had $\mathrm{HbA1c}$ less than $7 \%$ whereas 23 (31.5\%) patients still had more than 7\%.

\begin{tabular}{|c|c|c|c|}
\hline & \multicolumn{3}{|c|}{ Patients with HbA1c $<7 \%$} \\
\hline & $\begin{array}{c}\text { Before Glycaemic } \\
\text { Control }\end{array}$ & $\begin{array}{c}\text { After Glycaemic } \\
\text { Control }\end{array}$ & $\begin{array}{c}\text { P } \\
\text { value }\end{array}$ \\
\hline$\% \mathrm{FAD}$ & $7.44 \pm 1.92$ & $10.23 \pm 1.94$ & $<0.05$ \\
\hline$\% \mathrm{GTN}$ & $13.51 \pm 3.10$ & $13.97 \pm 3.33$ & $>0.05$ \\
\hline & \multicolumn{2}{|c|}{ Patients with HbA1c $>7 \%$} \\
\hline & $\begin{array}{c}\text { Before Glycaemic } \\
\text { Control }\end{array}$ & $\begin{array}{c}\text { After Glycaemic } \\
\text { Control }\end{array}$ & $\begin{array}{c}\text { P } \\
\text { value }\end{array}$ \\
\hline$\% \mathrm{FAD}$ & $7.13 \pm 2.65$ & $8.64 \pm 2.70$ & $>0.05$ \\
\hline$\% \mathrm{GTN}$ & $15.39 \pm 2.18$ & $15.53 \pm 2.04$ & $>0.05$ \\
\hline \multicolumn{4}{|c|}{ Table 4. Comparison of Endothelial Function in } \\
Patients with HbA1c less than and more \\
than 7\% before and after Glycaemic Control \\
\hline \multicolumn{4}{|c|}{}
\end{tabular}

Significant reduction in HbA1c was observed in patients with $\mathrm{HbA} 1 \mathrm{c}<7 \%$ as well as those with HbA1c $>7 \%$ ( $\mathrm{p}<0.05)$. Percentage FAD significantly increased after glycaemic control in patients with HbA1c less than $7 \%(\mathrm{p}<0.05)$. However, there was no significant difference in \%GTN in patients with $\mathrm{HbA} 1 \mathrm{c}$ less than or more than $7 \%(\mathrm{p}>0.05)$. Percentage FAD did not improve in patients with baseline HbA1c more than 7\% (Table 4; $p>0.05$ ). After three months of antidiabetic therapy, reduction in $\operatorname{HbA1c}(\mathrm{p}<0.05)$ and percentage improvement in FAD $(\mathrm{p}<0.01)$ was significantly better in those with baseline value of less than $7 \%$ compared to those with more than $7 \%$.

On correlating various variables with endotheliumdependent dilation (\%FAD) at baseline, it was found that HbA1c ( $r$ value-0.266; $p=0.023$ ) and BMI ( $r$ value- 0.263 ; $\mathrm{p}=0.02$ ) had significantly negative correlation with $\% \mathrm{FAD}$. Age and duration of diabetes also had negative correlation with endothelium-dependent dilation but it was not statistically significant (age $r$ value- $0.130 ; p=0.27$; duration of diabetes $r$ value-0.206; $p=0.79$ ). After glycaemic control also $\mathrm{HbA1c}$ and BMI were found to have a significant negative correlation with \% FAD (HbA1c $r$ value - 0.403; $p=0.00$; BMI $r$ value-0.240; $\mathrm{p}=0.041$ ). Age and duration of diabetes also had negative correlation with endothelium dependent dilation but it was not statistically significant (age $r$ value-0.097; $\mathrm{p}=0.414$; duration of diabetes $\mathrm{r}$ value- $0.221 ; \mathrm{p}=0.061$ ). No correlation was found between lipid profile and endothelial function before or after treatment.

\section{DISCUSSION}

Endothelial dysfunction, a common problem in patients with uncontrolled diabetes is a risk factor for multiple complications. Several studies have evaluated endothelial dysfunction in type 2 diabetes patients with control group ${ }^{10-13}$ or without control group. ${ }^{14}$ In this observational study, we evaluated endothelial dysfunction in uncontrolled type 2 diabetes mellitus and the influence of glycaemic control on endothelial function in these patients. For ensuring inadequately controlled diabetes, we enrolled cases with HbA1c more than $7 \%$. The mean BMI of patients in our study i.e. $24.67 \pm 1.75 \mathrm{~kg} / \mathrm{m}^{2}$ was lower than others. ${ }^{10,12}$ Normal 
weight in majority patients in our study shows that endothelial dysfunction is possible irrespective of obesity or overweight in diabetes patients. Similar to another study, 14 we also recruited cases of type 2 diabetes with less than 15 years duration. The mean duration of diabetes in another study ${ }^{10}$ was 6.7 years compared to 4.84 years in our study.

Doppler study of brachial artery is an established method of non-invasive assessment of endothelial function. ${ }^{7}$ Diameters of the femoral and brachial arteries are measured during reactive hyperaemia and after sublingual administration of glyceryl trinitrate, both procedures inducing vasodilation; former mediated by endothelium dependent mechanism whereas the latter acts directly on smooth muscle cells (Endothelium-independent). Comparison of vasodilation produced by different mechanisms enables non-invasive assessment of endothelial function.

Endothelium dependent dilation (\%FAD) is impaired in uncontrolled type 2 diabetes. ${ }^{10}$ Endothelial dysfunction was observed in $89 \%$ cases in our study as opposed to $78.6 \%$ in another study. ${ }^{9}$ In our study, at baseline, endothelium dependent dilation was significantly impaired as compared to endothelium-independent dilation in patients with inadequately controlled type 2 diabetes patients.

The mean percent increase in lumen diameter of brachial artery after stress i.e. reactive hyperaemia (\%FAD) improved after glycaemic control suggesting improvement in endothelial-dependent dilation. Percentage FAD significantly increased after glycaemic control in patients with $\mathrm{HbA1c}$ $<7 \%$. However, there was no improvement in \%FAD in patients with baseline $\mathrm{HbA} 1 \mathrm{c}>7 \%$ indicating no significant improvement in endothelial function despite significant improvement in glycaemic status. In our study, \%FAD was significantly impaired as compared to \%GTN which suggest that endothelium-dependent vasodilation is significantly lower in poorly controlled diabetic cases than endotheliumindependent vasodilation. Our findings are in accordance with previously reported findings. ${ }^{14}$ A comparative trial ${ }^{12}$ studied endothelial function in diabetic patients invasively and reported that endothelial dysfunction is more common in diabetic patients compared to controls. However, they did not find difference in endothelium-dependent (\%FAD) and endothelium-independent dilation (\%GTN). According to them, blunted vasodilator response to glyceryl trinitrate suggests that dysfunctional endothelium is not solely responsible for the impaired vascular relaxation in diabetic patients. As glyceryl trinitrate and endothelium derived relaxing factor (EDRF) share a common final pathway for vasodilation, a selective defect in the diabetic vasculature might be responsible for the impaired responses to such nitrovasodilators.

Many studies ${ }^{15-17}$ demonstrated endothelial dysfunction in type 2 DM patients while some studies ${ }^{18-21}$ provide conflicting data regarding endothelium-independent dilation (\%GTN). Our study also demonstrates impaired \%FAD in uncontrolled diabetic cases. Percentage FAD is a marker of endothelium mediated dilation. It indicates release of endothelium EDRF or nitric oxide. It is contended that diabetes is associated with a deficiency of bioactive nitric oxide and accompanied by alteration in vessel architecture resulting in overall reduced dilatory capacity of resistance vessel. We observed significantly lower mean \%FAD in diabetes patients. The mean $\% \mathrm{FAD}$ in our study was less than $10 \%$. Our findings strongly support the presence of endothelial dysfunction in type 2 diabetes patients.

After glycaemic control there was statistically significant improvement in \%FAD. A study 10 evaluated endotheliumdependent vasodilation (\%FAD) and endotheliumindependent vasodilation (\%GTN) after insulin therapy. Before glycaemic control \%FAD and \%GTN were $2.7 \pm 2.2$ and 14.4 \pm 3.6 respectively. After glycaemic control, \%FAD was $5.0 \pm 2.8$ whereas $\%$ GTN was $14.1 \pm 2.8$.

Another study evaluating endothelial dysfunction in uncontrolled diabetes cases demonstrated statistical difference between \%FAD vs. \%GTN before and after glycaemic control.14

The mean percentage of endothelium-dependent dilation was less than $10 \%$ in our study. After glycaemic control though mean \%FAD improved, it was less than $10 \%$ which suggests that endothelial dysfunction was still present. These finding suggests that endothelial function may not become normal even after glycaemic control. Only relative improvement in endothelial function after glycaemic control suggests presence of other factors contributing to endothelial dysfunction in diabetes patients.

W. Bagg et al ${ }^{14}$ did not observe significant endothelialdependent dilation after glycaemic control possibly because of the involvement of more advanced cases in the study. In addition to endothelial dysfunction, structural changes within the arterial wall could prevent an improvement of \%FAD.

We observed significant negative correlation between endothelium-dependent dilation and glycated haemoglobin i.e. with increase in glycated haemoglobin, there was decrease in endothelium-dependent dilation. Gaenzer et al ${ }^{10}$ also reported that absolute change in endotheliumdependent dilation has significant negative correlations with HbA1c $(r=-0.67, p<0.001)$. However, another study ${ }^{12}$ showed no correlation between endothelium-dependent dilation and HbA1c.

Overall observations indicate need of strict monitoring and control of glycaemic status of the patients to avoid development of endothelial dysfunction. Prevention of endothelial dysfunction would always be better than trying to treat it. Better glycaemic control will help in improvement of endothelial function and reducing further complications of diabetes. Prospective study with larger sample size is required to evaluate effect of intensive glycaemic control on endothelial function and assess correlation between endothelial dysfunction and glycaemic status.

Our study has some limitations. An observational study from single centre with defined age group limits generalisation of findings to overall population of diabetes mellitus. Absence of control group and short duration of therapy are the other limitations of study.

\section{CONCLUSION}

Uncontrolled type 2 diabetes mellitus is associated with impaired endothelial function which may be attributable to poor glycaemic status. There is negative correlation between endothelial dysfunction and glycaemic status of type 2 diabetes patients. Endothelial dysfunction improves after achieving glycaemic control. 


\section{REFERENCES}

[1] Avogaro A, Albiero M, Menegazzo L, et al. Endothelial dysfunction in diabetes: the role of reparatory mechanisms. Diabetes Care 2011;34(Suppl 2): S285-90.

[2] Tabit CE, Chung WB, Hamburg NM, et al. Endothelial dysfunction in diabetes mellitus: molecular mechanisms and clinical implications. Rev Endocr Metab Disord 2010;11(1):61-74.

[3] Hadi HAR, Al Suwaidi J. Endothelial dysfunction in diabetes mellitus. Vas Health Risk Manag 2007;3(6):853-76.

[4] Gopaul NK, Manraj MD, Hebe A, et al. Oxidative stress could precede endothelial dysfunction and insulin resistance in Indian Mauritians with impaired glucose metabolism. Diabetologia 2001;44(6):706-12.

[5] Dhananjayan R, Malati T, Brindha G, et al. Association of family history of type 2 diabetes mellitus with markers of endothelial dysfunction in South Indian population. Indian J Biochem Biophys 2013; 50(2):93-8.

[6] Nandyala V, Gandiah P, Kumar HJ, et al. Evaluation of endothelial dysfunction in patients with type 2 diabetes mellitus-analysis of 100 cases. International Journal of Biomedical and Advance Research 2016;7(2):58-63.

[7] Celermajer DS, Sorensen KE, Gooch VM, et al. Noninvasive detection of endothelia dysfunction in children and adults at risk of atherosclerosis. Lancet 1992;340(8828):1111-5.

[8] Satpathy PK, Diggikar PM, Rupnar PB, et al. Study of endothelial dysfunction in diabetes mellitus by Doppler flow mediated dilation of brachial artery. J Assoc Physicians India 2014;62(4):364-5.

[9] Bosevski M, Borozanov V, Peovska I, et al. Endothelial dysfunction correlates with plasma fibrinogen and HDL cholesterol in type 2 diabetic patients with coronary artery disease. Bratisl Lek Listy 2007;108(7):297-300.

[10] Gaenzer H, Neumayr G, Marschang P, et al. Effect of insulin therapy on endothelium-dependent dilation in type 2 diabetes mellitus. The Am J Cardiol 2002;89(4):431-4.

[11] Bagg W, Ferri C, Desideri G, et al. The influences of obesity and glycaemic control on endothelial activation in patients with type 2 diabetes. J Clin Endocrinol Metab 2001;86(11):5491-7.
[12] McVeigh GE, Brennan GM, Johnston GD, et al. Impaired endothelium-dependent and independent vasodilation in type 2 (non-insulin-dependent) diabetes mellitus. Diabetologia 1992;35(8):771-6.

[13] Mather KJ, Verma S, Anderson TJ. Improved endothelial function with metformin in type 2 diabetes mellitus. J Am Coll Cardiol 2001;37(5):1344-50.

[14] Bagg W, Whalley GA, Gamble G, et al. Effects of improved glycaemic control on endothelial function in patients with type 2 diabetes. Int Med J 2001;31(6):322-8.

[15] Vehkavaara S, Makimattila S, Schlenzka A, et al. Insulin therapy improves endothelial function in type 2 diabetes. Arterioscler Thromb Vasc Biol 2000;20(2):545-50.

[16] Williams SB, Cusco JA, Roddy MA, et al. Impaired nitric oxide-mediated vasodilation in patients with noninsulin-dependent diabetes mellitus. J Am Coll Cardiol 1996;27(3):567-74.

[17] Ting HH, Timimi FK, Boles KS, et al. Vitamin C improves endothelium-dependent vasodilation in patients with non-insulin dependent diabetes mellitus. J Clin Invest 1996;97(1):22-8.

[18] Gazis A, White DJ, Page SR, et al. Effect of oral vitamin E (alpha-tocopherol) supplementation on vascular endothelial function in type 2 diabetes mellitus. Diabet Med 1999;16(4):304-11.

[19] Enderle MD, Benda N, Schmuelling RM, et al. Preserved endothelial function in IDDM patients, but not in NIDDM patients, compared with healthy subjects. Diabetes Care 1998;21(2):271-7.

[20] Balletshofer BM, Rittig K, Enderle MD, et al. Endothelial dysfunction is detectable in young normotensive first-degree relatives of subjects with type 2 diabetes in association with insulin resistance. Circulation 2000;101(15):1780-4.

[21] Watts GF, O'brien SF, Silvester W, et al. Impaired endothelium dependent and independent dilation of forearm resistance arteries in men with diet-treated non-insulin-dependent diabetes: role of dyslipidaemia. Clin Sci 1996;91(5):567-73. 